\title{
Structural and biological properties of peptide nucleic acid (PNA)
}

\author{
Peter E. Nielsen \\ Center for Biomolecular Recognition, Department of Medical Biochemistry \& Genetics, \\ Biochemistry Lab. B. The Panum Institute, Blegdamsvej 3c, DK-2200 N, Copenhagen, Denmark
}

Abstract: The chemical, physical and biological properties of PNA (peptide nucleic acid) is briefly reviewed. In particular, recent X-ray crystallography and NMR structural data on PNA complexes are discussed. Furthermore, effects of backbone or nucleobase modifications on the PNA nucleic acid hybridization properties are discussed.

\section{INTRODUCTION}

PNA (peptide nucleic acid) is a DNA mimic with a pseudo peptide backbone composed of N-(2-amino ethyl)glycine units (1-3) (Figure 1). PNA oligomers are conveniently synthesized by conventional tBoc- or Fmoc-solid support peptide chemistry (4-6), and they hybridize with high efficiency and sequence specificity to Watson-Crick complementary (anti-parallel) DNA, RNA or PNA oligomers (7) forming helical duplexes. In analogy to natural nucleic acids, homopyrimidine PNA oligomers form PNA $_{2}$-NA triplexes with complementary homo-purine nucleic acids $(2,8)$ and such triplexes show unprecedented high thermal stability $(2,9,10)$.

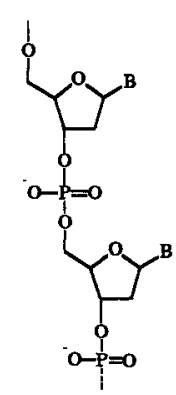

DNA

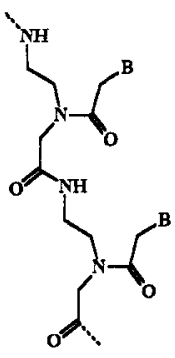

PNA
Figure 1. Chemical structures of DNA and PNA

PNA was originally designed as a reagent for sequence specific recognition of double stranded DNA via triplex binding in the major groove of the DNA double helix (1). Surprisingly, however, homopyrimidine PNAs prefer binding to their homopurine duplex DNA target by strand displacement $(1,11,12)$ via formation of an internal PNA - DNA - PNA triplex (12) (Figure 2).

These properties of PNA combined with their high chemical and not least biological stability (13) have made PNA a very attractive lead compound for the development of gene therapeutic agent by the antisense or antigene strategy (14-18). Furthermore, several diagnostic and molecular biology techniques have been developed using PNA as a tool (19-23). Finally, the fundamental DNA mimicking properties of PNA are of interest from a primordial evolutionary point of view (24-26) as well as for discussions concerning the structural role of the nucleobases versus the backbone in nucleic acid structures (27). Therefore it is of interest to study the chemical and structural properties of PNA per se. 


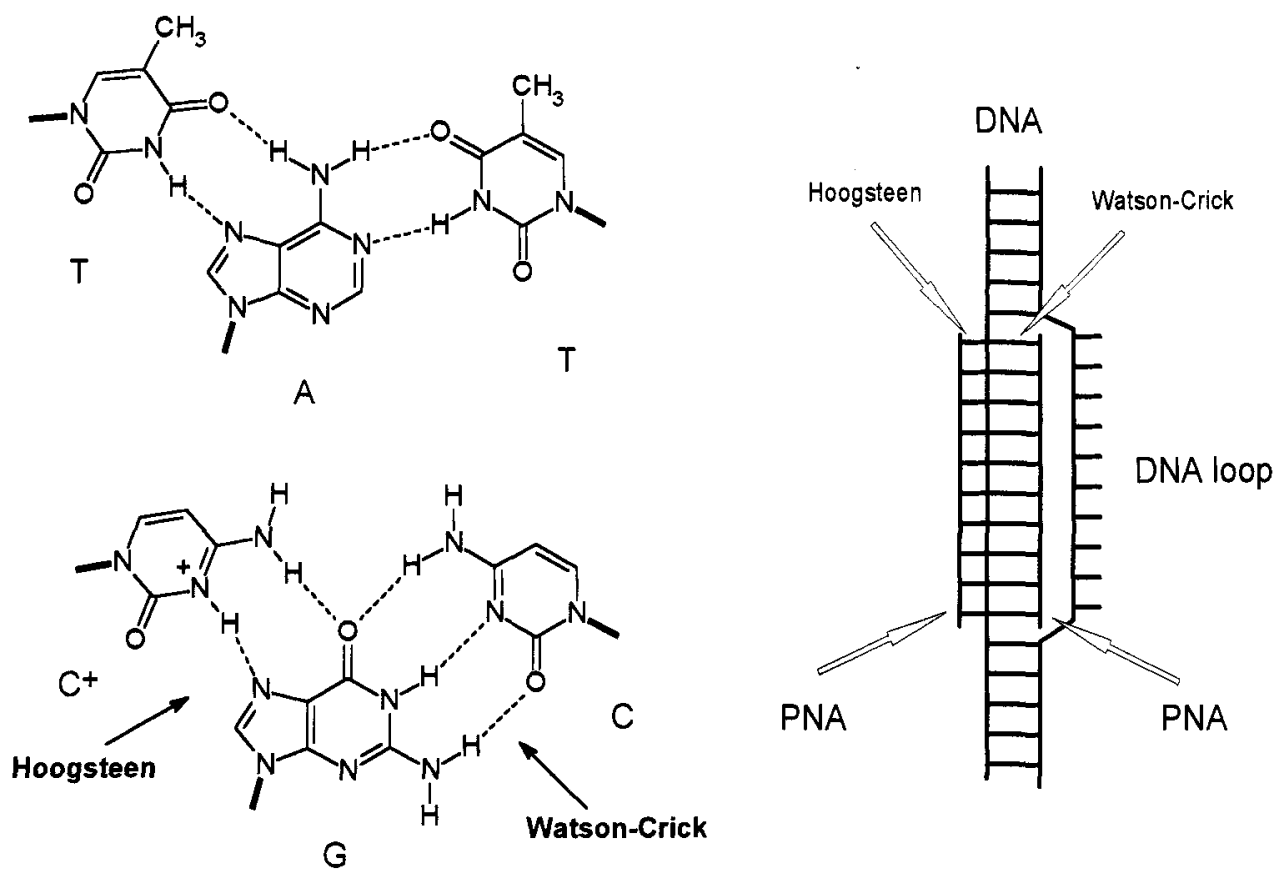

Figure 2. Schematic drawing of a PNA-dsDNA strand displacement complex (right) consisting of two PNA strands (composed of thymines (T) and cytosines (C)) that invade the DNA duplex and bind to the complementary DNA strand (composed of adenines (A) and guanines (G)) by Watson-Crick and Hoogsteen base pairing (left). The non-complementary DNA strand is extruded as a single stranded loop.

\section{STRUCTURE OF PNA COMPLEXES}

To date four "PNA structures" have been solved. The structures of a PNA-RNA (28) and a PNA-DNA (29) duplex were obtained by NMR methods, while those of a PNA $_{2}$-DNA triplex (30) and a PNA-PNA duplex (31) were solved by X-ray crystallography. Briefly, these results show that PNA is able to adapt to its nucleotide partner since the conformation of the RNA strand in the PNA-RNA duplex is essentially A-form, while that of the DNA strand in the PNA-DNA duplex is closer to a B-form. Most interestingly, however, the $\mathrm{X}$-ray structures of the $\mathrm{PNA}_{2}$-DNA triplex, and especially that of the PNA duplex show that PNA actually prefers a distinctly different helical structure, the P-form, which has a large pitch (18 bases) as well as a large (28 A) diameter. Nonetheless, the base pairs are perpendicular to the helix axis and exhibit close to A-form base pair overlaps. Thus it may be argued that although PNA is indeed a good structural mimic of DNA (or RNA) showing excellent hybridization and sequence discrimination properties, it is, of course, not a perfect mimic. Thus there should be plenty of opportunity for chemistry efforts to improve the DNA/RNA binding properties of peptide nucleic acid. Such studies naturally also serve the purpose of delineating the structureactivity relations of these DNA mimics in order to better understand their structural properties from a chemical perspective $(27,32)$ 

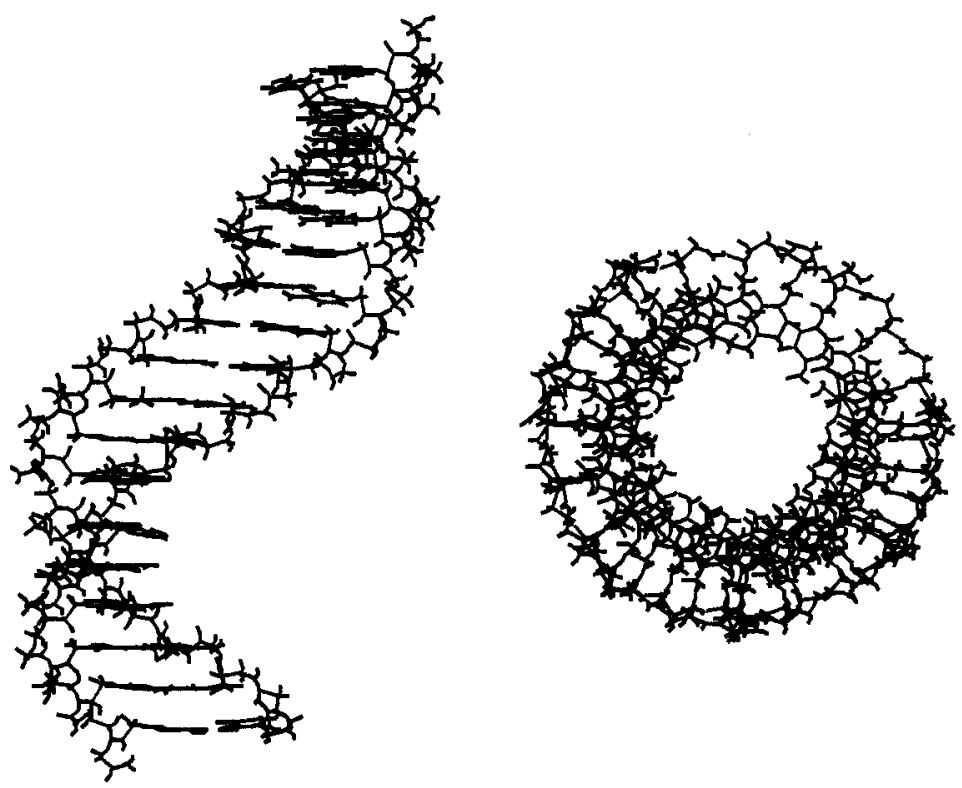

Figure 3. Structure of an 18-mer PNA duplex build from the X-ray crystallography data obtained from a selfcomplementary hexamer PNA (31). Side (left) and end (right) -views are shown

\section{BACKBONE MODIFIED PNAs}

Modifications of the original N-acetyl-N-(2-amino ethyl)glycine PNA backbone have not yet yielded derivatives that hybridize more strongly to DNA or RNA (27). Therefore, this backbone seems to exhibit the favorable constrained flexibility required of a non-cyclic backbone. Nonetheless, further constraining the backbone by cyclizing analogues to the sugars of DNA and RNA could well produce PNAs of improved hybridization efficiency provided that cyclic structures - that confine the backbone to the correct conformation in terms of low energy PNA-NA duplexes - can be found. Several attempts in this direction have already been conducted. Jordan et al. synthesized various amino proline based backbones and preliminary data indicate one of these (Figure 4) to exhibit good hybridization properties (33). We have constrained the backbone by substituting the ethyl part of the linker by a cyclohexyl moiety and the S,S-isomer shows hybridization properties comparable to those of the parent PNA (34). More importantly, however, thermodynamic measurements indicated a significant reduction in entropy loss upon hybridization as would be expected for using a more constrained backbone. Unfortunately, this more favorable entropic situation was fully counterbalanced by the decrease in enthalpic gain upon hybridization. It therefore appears that we did succeed in constraining the flexibility of the backbone, but at a low energy conformation that is different from the one preferred in the final PNA-NA complex. 


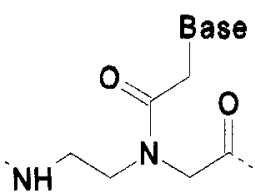

PNA<smiles>NC1CCCCC1N(CC(=O)O)C(=O)CC(=O)O</smiles>

Cyclohexyl PNA

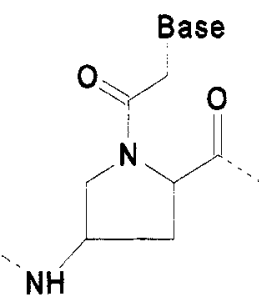

Aminoproline PNA

Figure 4. Chemical structures of "cyclic PNAs".

Simple substitutions at the $\alpha$-carbon of the glycine moiety of the backbone have been successful. Several of the natural D- or L- $\alpha$-amino acids can be used without seriously affecting the hybridization of the PNA oligomers (35). This approach therefore provides a very versatile means to modify and tailor-make the physico-chemical properties of PNA, and thereby properties that determine its pharmacokinetic and bioavailability properties.

\section{ALTERNATIVE NUCLEOBASES}

Only few nonstandard nucleobases have so far been reported in a PNA context. Pseudoisocytosine has proven very efficient as a "permanently protonated" cytosine analogue for Hoogsteen recognition of guanine in $\mathrm{PNA}_{2}-$ NA triplexes $(11,22)$, and recently we found that substitution of adenine for diaminopurine results in PNA with significantly improved hybridization properties. Diaminopurine can form three hydrogen bonds with thymine (Figure 5.) and thus increases the stability of the complexes. Due to the versatility of PNA/peptide chemistry the future will undoubtedly bring many other (new) alternative nucleobases in PNA technology designed for specific purposes, not least the recognition of $\mathrm{I}-\mathrm{A}$ adn $\underline{\mathrm{C}}-\mathrm{G}$ base pairs in triple helices.

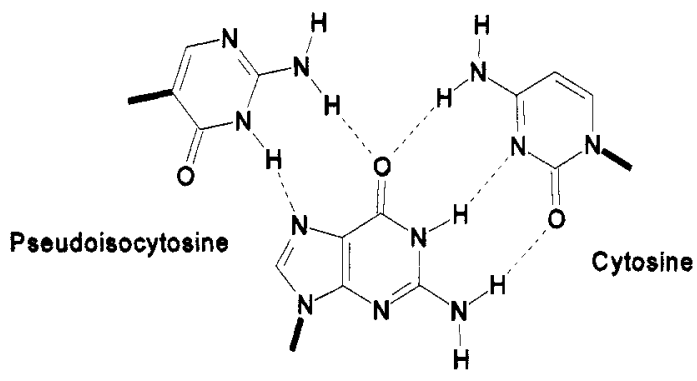

Guanine

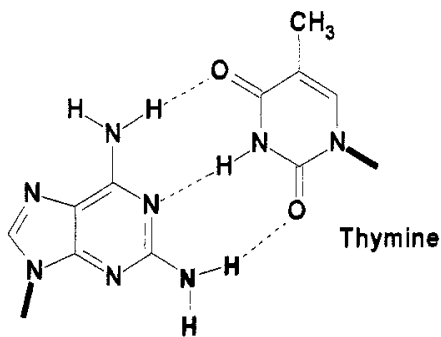

Diaminopurine

Figure 5. Chemical structures of pseudoisocytosine-G-C triplet and diaminopurine-T base pair 


\section{PROSPECTS}

The properties of PNA as revealed so far clearly position this type of DNA mimic as an important player in the development of gene therapeutic agents, in the development of genetic diagnostic technology both in medicine and molecular biology and also as molecular recognition system in its own right with interesting chemical and physical properties $(27,36)$. The PNA work has even inspired the development of "peptides" that could be eventually be used for optical information storage. Thus a project that started out as an "exercise" in dsDNA recognition has opened doors to quite a broad variety of chemical, biological, medicinal and even material science fields.

\section{ACKNOWLEDGMENT}

This work was supported by the Danish National Research Foundation.

\section{REFERENCES}

1. Nielsen, P.E., Egholm, M., Berg, R.H. \& Buchardt, O. (1991) Science 254, 1497-1500.

2. Egholm, M., Buchardt, O., Nielsen, P.E. \& Berg, R.H. (1992) J. Amer. Chem. Soc. 114, 1895-1897.

3. Hyrup, B. \& Nielsen, P.E. (1996) (review) Bioorg. Biomed. Chem. 4, 5-23.

4. Dueholm, K.L., Egholm, M., Behrens, C., Christensen, L., Hansen, H.F., Vulpius, T., Petersen, K., Berg, R.H., Nielsen, P.E. \& Buchardt, O. (1994) J. Org. Chem. 59, 5767-5773.

5. Christensen, L., Fitzpatrick, R., Gildea, B., Petersen, K.H., Hansen, H.F., Koch, T., Egholm, M., Buchardt, O., Nielsen, P.E., Coull, J. \& Berg, R.H. (1995) J. Peptide Sci. 3, 175-183.

6. Thomson, S.A., Josey, J.A., Cadilla, R., Gaul, M.D., Hassman, F.C., Luzzio, M.J, Pipe, A.J., Reed, K.L., Ricca, D.J., Wiethe, R.W. \& Noble, S.A. (1995) Tetrahedron 51, 6179-6194.

7. Egholm, M., Buchardt, O., Christensen, L., Behrens, C., Freier, S.M., Driver, D.A., Berg, R.H., Kim, S.K., Nordén, B. \& Nielsen, P.E. (1993) Nature 365, 556-568.

8. Kim, S.K., Nielsen, P.E., Egholm, M., Buchardt, O., Berg, R.H. \& Nordén, B. (1993) J. Amer. Chem. Soc. 115, 6477-6481.

9. Egholm, M., Behrens, C., Christensen, L., Berg, R.H., Nielsen, P.E. \& Buchardt, O. (1993) J. Chem. Soc. Chem. Commun. 800-801.

10. Egholm, M., Christensen, L., Dueholm, K., Buchardt, O., Coull, J. \& Nielsen, P.E. (1995) Nucleic Acids Res. 23, $217-222$.

11. Cherny, D.Y., Belotserkovskii, B.P., Frank-Kamenetskii, M.D., Egholm, M., Buchardt, O., Berg, R.H. \& Nielsen, P.E. (1993) Proc. Natl. Acad. Sci. USA. 90, 1667-1670.

12. Nielsen, P.E., Egholm, M. \& Buchardt, O. (1994) J. Mol. Recognition. 7, $165-70$.

13. Demidov, V., Potaman, V.N., Frank-Kamenetskii, M.D., Buchardt, O., Egholm, M., \& Nielsen, P.E. (1994) Biochem. Pharmacol. 48, 1309-1313.

14. Hanvey, J.C., Peffer, N.C., Bisi, J.E., Thomson, S.A., Cadilla, R., Josey, J.A., Ricca, D.J., Hassman, C.F., Bonham, M.A., Au, K.G., Carter, S.G., Bruckenstein D.A., Boyd, A:L., Noble S.A. \& Babiss, L.E. (1992) Science 258, 1481-1485. 15. Nielsen, P.E., Egholm, M. \& Buchardt, O. (1994) Gene 149, 139-145.

16. Bonham, M.A., Brown, S., Boyd, A.L., Brown, P.H., Bruckenstein, D.A., Hanvey, J.C., Thomson, S.A., Pipe, A. . Hassman, F., Bisi, J.E., Froehler, B.C., Matteucci, M.D., Wagner, R.W., Noble, S.A. \& Babiss, L.E. (1995) Nucleic Acids Res. 23, 1197-1203.

17. Knudsen, H. \& Nielsen, P.E. (1996) Nucleic Acids Res. 24, 494-500.

18. Norton, JC; Piatyczek, MA; Wright, WE; Shay JW \& Corey DR (1996) Nature Biotechnology 14, 615-619.

19. Ørum, H., Nielsen, P.E., Egholm, M., Berg, R.H., Buchardt, O. \& Stanley, C. (1993) Nucleic Acids Res. 21, $5332-5336$. 
20. Nielsen, P.E. \& Ørum, H. (1995) in Molecular Biology: Current Innovations and Future Trends (H. Griffin, ed.) Horizon Scientific Press, UK, p.73-86.

21. Ørum, H., Jørgensen, M., Koch, T., Nielsen, P.E., Larsson, C. \& Stanley, C. (1995) Biotechniques 19, 472-480.

22. Veselkov, A.G., Demidov, V.V., Nielsen, P.E. \& Frank-Kamenetskii, M. (1996) Nucl. Acids Res. 24, $2483-2487$.

23. Wang, J., Palecek, E., Nielsen, P.E., Rivas, G., Cai, X., Shiraishi, H., Dontha, N., Luo, D. \& Farias, M.A. (1996) J. Amer. Chem. Soc. 118, 7667-7670.

24. Nielsen, P.E. (1993) Origins of Life 23, 323-327.

25. Böhler, C., Nielsen, P.E. \& Orgel, L.E. (1995) Nature 376, 578-581.

26. Schmidt, J.G, Nielsen, P.E. \& Orgel, L.E. (1997) J. Amer. Chem. Soc. 119.

27. Nielsen, P.E. \& Haama, G (1997) Chemical Society Reviews. 26, 73-78..

28. Brown S.C. Thomson S.A., Veal J.M., Davis, D.G. (1994) Science 265, 777-780.

29. Eriksson, M. \& Nielsen, P.E. (1996) Nature Structural Biology $\underline{3} 410-413$.

30. Betts, L., Josey, J.A., Veal, J.M., Jordan, S.R. (1995) Science 270, 1838-1841.

31. Rasmussen, H., Kastrup, J.S., Nielsen, J.N., Nielsen, J.M. \& Nielsen, P.E. (1997) Nature Structural Biology 4, 98-101.

32. Eriksson, M. \& Nielsen, P. E. (1996)Quart. Rev. Biophysics 29,369-394.

33. Jordan, S., Schwemler, C., Kosch, W., Kretschmer, A., Stropp, U, Schwenner, E \& Mielke, B. (1997) Bioorg. Biomed. Chem. Lett.7, 687-690

34. Lagriffoule, P., Buchardt, O., Wittung, P., Nordén, B., Jensen, K.K. \& Nielsen, P.E.(1997) Chem. Eur. J. (In press)

35. Haaima, G., Lohse, A., Buchardt, O. \& Nielsen, P.E. (1996) Angewandte Chemie 35, 1939-1941.

36. Berg, R. H., Hvilsted, S. \& Ramanujan, P. S. Nature (1996) 6. 505-507. 